\title{
EDITORIAL
}

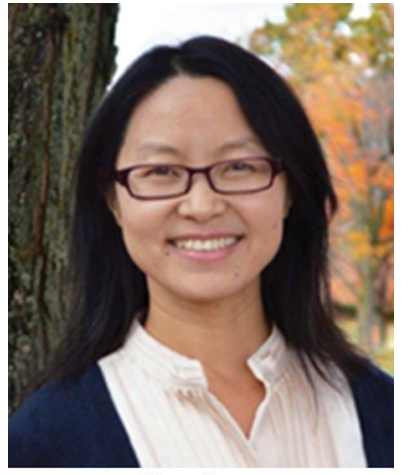

Yan Lu

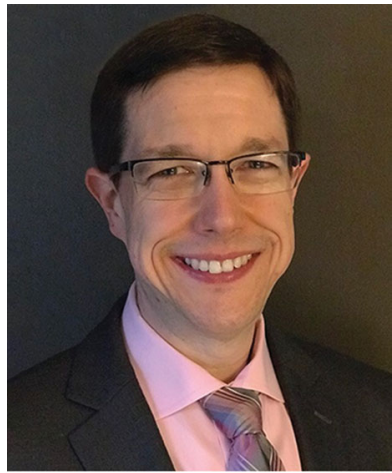

Brandon Ribic

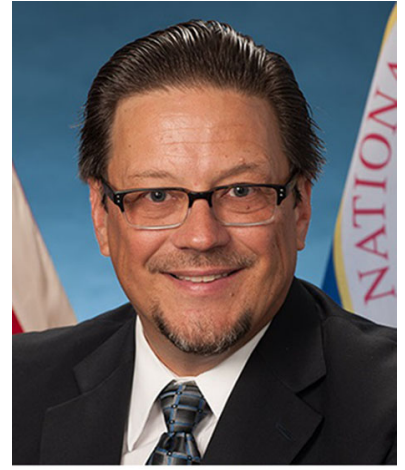

Richard Russell

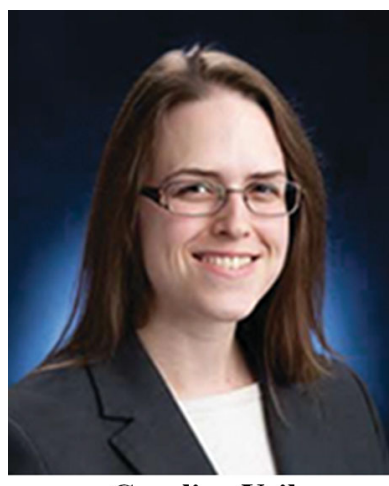

Caroline Vail

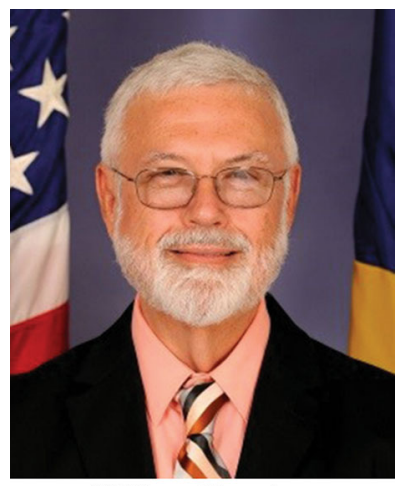

Willam Frazier

\section{Special Issues on Additive Manufacturing}

Additive manufacturing (AM) is a nascent and rapidly evolving technology of significant commercial importance. This special focus issue was designed to explore the complex relationship between processing, microstructure, properties, and performance of AM materials. The material science and engineering community responded to the call for papers by contributing an outstanding array of quality and technically diverse manuscripts. As a result of the large number of high-quality papers accepted for publication, manuscripts are published in both the July and September 2021 issues of JMEP. Of additional value, four chapters of the recently published ASM Handbook, Volume 24, Additive Manufacturing Processes have been included. Two of these articles will appear in each of the special issues. Their subject matter includes (i) Aerosol Jetting for Multifunctional AM, (ii) Defects in Metal AM Processes, (iii) Vat-Photopolymerization Based Ceramic Manufacturing, and (iv) AM of Titanium Alloys.

The manuscripts published in this special issue were subject to the journal's normal rigorous peer review process and were scrupulously examined by JMEP reviewers and editors. I commend the work of the 
journal's associate editors; furthermore, for their assiduous hard work, I wish to convey my personal special thanks to the renowned cadre of guest editors. Their AM subject matter expertise and experience both improved the content of this special issue and expedited the review process.

The following guest editors contributed their time and talents to the issue:

Dr. Yan Lu is a member of the System Integration Division of the Engineering Laboratory at National Institute of Standards and Technology where she is a project lead for Data Integration and Management for Additive Manufacturing research. Her research interests include AM data modeling, data management, data registration, and data fusion. Her group has developed an open additive manufacturing material database, AMMD, supporting collaborative schema development and AM data sharing. Dr. Lu graduated from Tsinghua University with a B.S. and M.S. in automation control theory and from Carnegie Mellon University with a Ph.D. in electrical and computer engineering. Before joining NIST, Dr. Lu was the head of Production Operation and Optimization Research Group at Siemens Corporation, Corporate Technology. She has published more than 70 peer-reviewed journal and conference papers and was granted more than 10 patents in industry and building automation technology. Dr. Yan Lu is a U.S. expert for IEC TC 65 and a member of ASTM, ASME, and IEEE. She is active in developing AM and smart manufacturing standards.

Dr. Brandon Ribic obtained his bachelor's and doctorate degrees in materials science and engineering from Pennsylvania State University. His doctoral thesis focused on numerical modeling of fusion welding processes, which has proved very useful to his endeavors in the development and qualification of laser metal AM processes. He joined the National Center for Defense Manufacturing and Machining (NCDMM) in October 2019 as the America Makes Technology Director. Driven by NCDMM, America Makes is the national accelerator for AM and the first of nine Manufacturing Innovation Institutes established and managed by the U.S. Department of Defense as public-private partnerships. Dr. Ribic is responsible for the curation of the Institute's AM Technology Roadmap as well as leading America Makes' efforts in the Additive Manufacturing Standardization Collaborative with ANSI.

Prior to joining NCDMM, Dr. Ribic was a joining processes and AM materials specialist at Rolls-Royce Corporation. He led the Materials Technology Center efforts in AM process modeling and in situ process monitoring. His research focused on welding and AM processes for various titanium and nickel superalloy gas turbine engine components. One of his most notable achievements is successfully developing, qualifying, and productionizing (TRL 7) the first ever CMSX-4 AM repair for Rolls-Royce.

Mr. Richard Russell currently holds the position of the NASA Technical Fellow for Materials, which he has held since 2016. He has a B.S. degree in metallurgical engineering from the University of Illinois and an M.S. degree from the University of Florida in materials and science and engineering. Mr. Russell began his career in 1986 at the Naval Aviation Depot in Pensacola, Fl. In 1989 he joined NASA's Kennedy Space Center supporting the Shuttle Engineering Project Office serving as a Materials and Processes Engineering expert. In 1996, he left NASA and worked in aircraft manufacturing and design at The Aerostructures Corporation in Nashville, Tenn., and Bell Helicopter in Ft. Worth, Texas. In 2001, Mr. Russell rejoined the Shuttle Program working for the United Space Alliance at Kennedy Space Center.

In 2004, Mr. Russell rejoined NASA serving as the Aging Aircraft Principal Engineer for the Orbiter Project Support Office. In 2009, he became a member of the Materials Science Division at the Kennedy Space Center supporting the Orion Multi-Purpose Crew Vehicle and assisting in the development of requirements for the Commercial Crew Program. In 2012, Mr. Russell was named Chief of the Materials and Processes Engineering Branch and in 2014, he joined the Commercial Crew Program as both the spacecraft and launch vehicle Systems Manager for Specialty Engineering (Materials and Processes and Fracture Control).

Dr. Caroline Vail holds doctoral and master's degrees in mechanical engineering from University of Maryland, Baltimore County. She currently leads research and development efforts in AM within the Navy at Naval Surface Warfare Center Carderock Division. Her work has included coordinating Navy-wide efforts to accelerate AM technology into the Fleet, research in AM materials and processes, and research in nonferrous welding and post-processing. She was instrumental in creating the Naval Sea Systems Command technical requirements for qualification and certification of metal powder bed fusion parts, thereby enabling their use in the Fleet.

\author{
William E. Frazier, Ph.D., FASM \\ Editor \\ Journal of Materials Engineering and Performance \\ frazierwe@gmail.com
}


Dr. William Frazier organized this special issue and led the team of guest editors within his capacity as Editor, JMEP. Dr. Frazier received his B.S., M.S., and Ph.D. degrees in materials engineering from Drexel University. He is a graduate of the Naval Aviation Executive Institute's Senior Executive Management Development Program, and the Defense Systems Management College's Advanced Program Management Curriculum.

Dr. Frazier founded Pilgrim Consulting LLC following a successful 39-year career within the Department of the Navy and upon retiring, held the positions of "The Navy Senior Scientist for Materials Engineering," and "The Chief Scientist for the Air Vehicle Department" at the Naval Air Systems Command (NAVAIR). $\mathrm{He}$ is a recognized expert in (i) materials qualification and certification, (ii) manufacturing and processing, (iii) AM, and (iv) strategic planning. Dr. Frazier was the technical architect of NAVAIR's strategic efforts to deploy AM technology to enhance operational readiness and reduce sustainment cost. He also led the technical effort culminating in the certification and flying of the Navy's first flight critical AM component, viz., the V22 Osprey engine nacelle link.

Publisher's Note Springer Nature remains neutral with regard to jurisdictional claims in published maps and institutional affiliations. 